\title{
SOBRE A DOCUMENTAÇÃO DA HISTÓRIA \\ DOS TRABALHADORES \\ DO RIO GRANDE DO SUL \\ EXISTENTE EM DOIS \\ ARQUIVOS EUROPEUS
}

Sílvia Regina Ferraz Petersen ${ }^{1}$

Este pequeno informe está dirigido particularmente àqueles pesquisadores que estão começando a investigar o tema da História dos trabalhadores, especialmente de militantes, organizações sindicais, partidos e outros grupos e que talvez ignorem a existência, na Europa, de dois importantes centros de documentação que têm prestado inestimáveis serviços à pesquisa, não só pela extensão e qualidade de seus acervos (principalmente coleções de jornais), como pela possibilidade da obtenção de cópias microfilmadas das mesmas, o que tem tornado disponíveis informações de outra forma inacessíveis aos pesquisadores.

Estou me referindo ao INTERNATIONAAL INSTITUUT VOOR SOCIALE GESCHIEDENIS, localizado em Amsterdam, e o ARCHIVO STORICO DEL MOVIMENTO OPERAIO BRASILIANO, em Milão.

Professora do Programa de Pós-Graduação em História da Universidade Federal do Rio Grande do Sul. 
O IIVSG foi fundado em 1935, com o propósito de resguardar a herança do movimento operário europeu, inicialmente do Partido Social Democrata Alemão, em uma conjuntura em que as organizações de esquerda eram duramente perseguidas pelo nazismo e quando na Rússia o stalinismo fazia da pesquisa histórica muitas vezes uma perigosa tarefa, ao ponto do Instituto Marx-Engels, fundado em 1920, em Moscou ter perdido seu diretor no grande expurgo.

Assim, arquivos e bibliotecas por toda a Europa em guerra precisavam ser resguardados e o Instituto passou a desempenhar, não sem riscos, este papel de guardião. Aos poucos foi adquirindo um impressionante acervo internacional de documentos privados, arquivos, periódicos e livros.

No que se refere particularmente à América Latina, a documentação mais representativa é procedente da coleção de Max Nettlau, historiador e bibliófilo anarquista austríaco que devotou parte de sua vida a reunir literatura anarquista de todo o mundo. Embora o anarquismo fosse seu interesse principal, outras correntes estão também representadas na documentação por ele recolhida.

Para o investigador brasileiro a documentação mais importante é a que trata do anarquismo e anarco-sindicalismo, do começo do século até os anos 20. Boa parte deste material pode ser também encontrado no Arquivo Edgard Leuenroth, da UNICAMP, que adquiriu cópias microfilmadas para seu acervo.

No caso do Rio Grande do Sul, são numerosas as coleções de jornais disponíveis no IIVSG, que passo a listar para o conhecimento dos pesquisadores interessados:

AKTION, Porto Alegre, 1933-37: I-IV, ns. 1-8, 10-70, 79, 81, 88-90.

ALARM, Porto Alegre, 1937: I, ns. 1-4.

A DEFEZA, Bagé, 1911:I, ns. 29, 30(*)2.

DEMOCRACIA SOCIAL, Pelotas, 1893:I, ns.1-6; 9-26(*).

ECHO OPERARIO, Rio Grande, 1897-1899:II-IV, ns. 55-64, 69-73, 76-83, 95-131, 133, 135(*).

O EXEMPLO, Porto Alegre, 1908-1911:VIII-XI (82 números).

2 Cópias microfilmadas dos jornais assinalados com $\left(^{*}\right)$ acham-se disponíveis no "Núcleo de Pesquisa em História/NPH" do Departamento e Programa de PósGraduação em História da UFRGS e já foram matéria de pesquisa para numerosas dissertações e outros trabalhos. 
DER FREIE ARBEITER, Porto Alegre, 1920-1930: I-IX (cerca de 150 números).

A LUTA, Porto Alegre, 1906:I, ns. 1-7; 1907:I, ns. 8-20, 22, II, ns. 2325; 1908:II, ns. 26, 28-35, III, ns. 36-40; 1909:III, ns. 41-46, IV, n. 47; 1910:IV, ns. 50-52, V, n. 53; 1911:IV, ns. 54-55 (*).

A LUTA, Pelotas, 1916: I, ns. 11, 12, 15, 16.

A LUTA, Porto Alegre, 1928:I, ns. 1-4; 1929: II, ns. 2-5, 7; 1930:III, ns. 1-3(*).

REVISTA LIBERAL, Porto Alegre, 1922:II, n. 16; 1923:III, n. 17.

O SYNDICALISTA, Porto Alegre, 1921:III, n. 4; 1924:VI, ns. 1-3; 1925:VII, n. 8; 1926:VIII, ns. 3, 5; 1927:VIII(sic), ns. 2-4, 7(*).

A VOZ DO TRABALHADOR, Porto Alęgre, 1912:I, n. 2.

A VOZ DO TRABALHADOR, Porto Alegre, 1933-1934 (23 números).

Ainda integra o acervo do IIVSG o livro de Florentino de Carvalho Da escravidão à liberdade (P. Alegre, Renascença, 1927, 241 p.) e uma carta de Giovani Rossi a Alfred G. Sanftleben, datada de Taquari, 29 de novembro de 1896.

Para possíveis consultas, o endereço do Arquivo é:

Cruquiusweg 31

NL-1019 AT-AMSTERDAM

Tel. 31-20-6685866; Fax 31-20-6654181

O segundo centro que desejo comentar é o Archivo Storico del Movimento Operario Brasiliano.

Nascido em Milão, em 1977, ao abrigo da Fundação Giangiacomo Feltrinelli, o AHMOB teve por objetivo reunir documentos (livros, revistas, escritos, fontes orais e iconográficas) sobre a história dos trabalhadores brasileiros em seus partidos políticos, sindicatos e organizações de massa. A conjuntura da ditadura militar dos anos 70, a repressão efetuada sobre os movimentos de trabalhadores e a destruição de sua memória fez com que, por iniciativa de intelectuais brasileiros e italianos, este arquivo fosse organizado.

Seu patrimônio consiste em documentos oferecidos por organizações políticas e sindicais assim como doações pessoais de militantes. Os principais fundos disponíveis são:

Arquivo de Astrogildo Pereira;

Arquivo de Roberto Morena; 
Arquivo de Tullio Seppilli;

Documentação da guerrilha brasileira (1968-1972);

Sons e imagens como fontes documentais;

Setor audio-visual.

Também conserva documentação sobre o exílio de brasileiros durante a ditadura militar e publicações de organizações de mulheres e de estudantes.

Com relação ao Rio Grande do Sul, estão disponíveis os seguintes jornais, que podem ser adquiridos em microfilmes:

A DOR HUMANA, Bagé, ns.1-6, 1919.

A LUTA, Porto Alegre, 1908, ns. 39, 44, 45; 1918, ns. 1-3.

A LUTA, Pelotas, 1916, ns. 1,7.

FOLHA DO POVO, Santa Maria, 1920 ns. 3, 4, 9, 11-13.

MARTELO E FOICE/HAMMER UND SICHEL, Porto Alegre, 1924, ns. 3-6, 9, 10.

REVISTA LIBERAL, Porto Alegre, 1921-1922, ns. 2-13.

O SYNDICALISTA, Porto Alegre 1921, n. 5; 1925, ns. 6-9; 1926, n. 2.

A UNIÃO, Uruguaiana, 1919, ns. 37, 39, 40, 42, 43, 46; 1920, n. 8.

Também estão arquivados os seguintes livros e folhetos:

ESTATUTOS da Federação Operária do Rio Grande do Sul. Porto Alegre, 1911, $6 \mathrm{p}$.

DO ANARCHISMO ao Comunismo. Porto Alegre, União dos Officios Vários, 1922, 40 p.

CENTRO Comunista N.4 (S.B.I.C.). Porto Alegre, 1925, 48 p.

NEQUETE, Abílio de. Technocracia ou o Quinto Estado. Porto Alegre, Globo, 1926, 41 p.

A correspondência para o AHMOB pode ser enviada para:

Archivo Storico del Movimento Operario Brasiliano

Giangiacomo Feltrinelli Foundation

Via Romagnosi, 3

Milano 20121

Tel.(02)864408 


\section{Bibliografia}

- GORDON, Eric e outros. A survey of Brazilian and Argentine materials at the International Instituut voor Sociale Geschiedenis in Amsterdam. Latin American Research Review, 8(3):27-77, 1973.

- DE JONG, Rudolf. Arquivos e História Social. Comunicação apresentada no Seminário 20 Anos de Arquivo Edgard Leuenroth. UNICAMP, agosto de 1994 (datilografado).

- CATÁLOGOS de microfilmes do Archivo Storico del Movimento Operario Brasiliano. Giangiacomo Feltrinelli Foundation, Milão, 1982 e 1983.

- MEMÓRIA e História. Revista do Arquivo Histórico do Movimento Operário Brasileiro. S. Paulo, Livraria Editora Ciências Humanas, 1981, n.1. 